\title{
La biblioteca como punto de partida hacia Internet: una propuesta
}

\section{Alfredo Vizcarro Broto}

\subsection{Resumen}

Se nos presenta a la biblioteca pública dotada con acceso a Internet como una plataforma idónea desde la que acceder a la información y adquirir una formación adecuada. En esta nueva biblioteca el rol del bibliotecario cambia, convirtiéndose en un introductor en las nuevas tecnologías. Como resultado de la introducción de la Internet, surge una nueva tipología de bibliotecas: digitales, tradicionales y mixtas.

Keywords: Biblioteca pública. Internet. Tipología bibliotecaria.

\subsection{Abstract}

The public library enhanced with Internet access is presented as a perfect platform to access information and get IT education and training. Such a new library will change the professional role of the librarian, transforming him/her into an information technology mediator. As a result of the introduction of Internet in libraries, a new tipology of them arises: digital, traditional and mixed.

Keywords: Public libraries. Internet. Libraries tipology.

Cuando se produce la eclosión de la revolución industrial comienza a acelerarse un fenómeno iniciado en el momento en que el hombre baja de un árbol de la sabana africana; dicho fenómeno cambiará de cara tras la segunda guerra mundial.

Hasta el conflicto bélico la tecnología se ocupaba de proporcionar medios e instrumentos para subsanar necesidades, que ya no eran satisfechas por inventos anteriores. Desde 1946 asistimos al hecho contrario: es la tecnología quien crea la demanda y construye una realidad colateral o artificial. El ejemplo típico de la primera etapa fue el ferrocarril. En los primeros momentos, se limitó civilmente su desarrollo con medidas sumamente curiosas. Podemos enumerar entre ellas: la obligación de llevar delante de la locomotora un señor con una bandera roja que avisara de la próxima llegada del artilugio, la imposibilidad de que circulara en 
domingo o la preferencia del peatón sobre el tren, si aquel deseaba cruzar una vía. Rápidamente el progreso arrumbó estas leyes y obligó a adecuar el marco jurídico al impulso ferroviario. Hoy somos testigos del hecho contrario: el fenómeno similar al tren, Internet (una larga serie de parecidos los emparentan, pero sobre todo uno, el de las consecuencias sociales) se desarrolla sin ningún tipo de regulación legislativa (no hablo de la autoimpuesta), con la particularidad de que la mayoría compartimos el deseo de no limitar la libertad actual. Sin embargo, la libertad conlleva riesgos cuando no se asume la dosis personal de responsabilidad que a cada uno toca. Esos posibles desmanes pueden resolverse o, al menos mitigarse, con la educación.

En este punto juegan un papel importante las bibliotecas de todo tipo — escolares, universitarias, especiales-, pero sobre todo, las bibliotecas públicas. Esos antros, que para mucha gente, son lugares donde se reúnen viejecillos que comentan los diarios, se puede consultar el BOE o tomar en préstamo la última novela de Javier Marías, pueden constituirse en una plataforma sin parangón para acceder al ciberespacio.

El carácter idóneo de la biblioteca pública para llevar a cabo esta honrosa tarea puede demostrarse mediante varias razones:

- El concepto de biblioteca pública engloba la noción de universalidad y la pretensión de servicio al ciudadano.

- Sus fines son ofrecer ocio, información y educación.

- El aprovechamiento de infraestructuras ya creadas (edificios, salas, ordenadores).

- Un personal familiarizado con Internet, con la recuperación de información y con la formación de usuarios en instrumentos de búsqueda.

Como resultado, la biblioteca añadiría a sus funciones la de ser una especie de academia para aquella gente que ya no está en la escuela (donde, según comentó la ministra Aguirre, la formación en Internet comenzaría en el aula infantil), ni puede afrontar costosos cursos de reciclaje, consiguiendo una fórmula democratizadora de propagación y acceso a Internet y las nuevas tecnologías.

En esta nueva biblioteca se resolverían las dudas que el manejo de las herramientas informáticas ocasiona y se pondría en contacto a la sociedad con un instrumento de aprendizaje de primera magnitud: la biblioteca como servicio de información/formación.

Por otra parte, el acceso se haría de forma natural y sería beneficioso para los dos sujetos que intervienen en la relación: el bibliotecario-formador y el usuarioformado. Ambos obtendrían una constatación de que el lema "aprender a aprender", que hará posible el desarrollo futuro en la esfera social y personal, es reali- 
zable.

Como consecuencia de todo lo dicho, algún agorero creerá que tiene fundamento una premonición como ésta: la biblioteca desaparecerá y sólo se accederá a estanterías y documentos virtuales (del átomo al bit).

Sin embargo, todos podemos respirar tranquilos, incluso el profeta, porque veremos convivir tres tipos de biblioteca, dos puros y uno mixto.

- El modelo siglo XX: En ella se hallará la misma documentación que ahora: libros, revistas, CDs, cintas. Lo táctil tendrá gran importancia. El libro se mantendrá como soporte físico, por su comodidad y fácil lectura (en un parque, una cocina, un café forrado de madera oscura). Se olerá el polvo depositado y se escucharán las respetuosas palabras del personal que te atiende.

- El modelo siglo XXI: El fondo documental estará en Internet, que es una gran biblioteca en la que podemos, y podremos todavía más, localizar archivos personales, literatura clásica, grabaciones de conciertos o retransmisiones de conferencias en tiempo real o en diferido. Lo audiovisual cobrará primacía. Las necesidades de información se resolverán a través del correo electrónico. Se establecerán perfiles de usuarios (amas de casa, inmigrantes, niños) y bookmarks para ellos.

- El modelo pasarela: En él se combinan los dos anteriores. Es el que debe surgir en este momento si los poderes públicos son conscientes del bien que puede aportar a la sociedad la divulgación de las nuevas tecnologías. El empujón se traduce en tomar la decisión de poner en marcha el proyecto sin más dilaciones y en dotar las bibliotecas de más personal cualificado.

Por todo ello constatamos cómo Internet llega a cualquier esfera conocida y la modifica. Incluso modifica una realidad considerada anacrónica por algunos políticos, como es la biblioteca pública, a la que actualmente se le niega dinero y personal, privilegiando servicios y gabinetes de asesoría, también necesarios, pero no tan democráticos. Para que la sociedad de la información sea universal y efectiva, el ciudadano requiere una formación inicial y una plataforma de entrada. Ambas pueden hacerse realidad desde la biblioteca pública. 